\title{
THE DISTRIBUTION OF ASH AND SULFUR IN IOWA COALS AS AFFECTED BY WASH- ING AND FLOTATION BY
}

H. L. OLIN and J. R. TROELTZSCH 



\section{CONTENTS}

Introduction

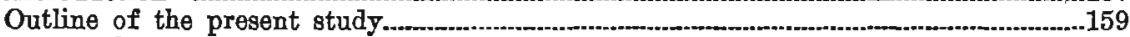

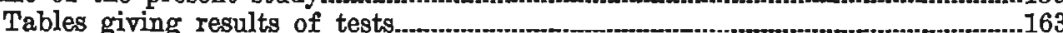

References …_.

\section{LIST OF ILLUSTRATIONS}

ITIGURE

PAGE

21 Details of sink-and-float apparatus

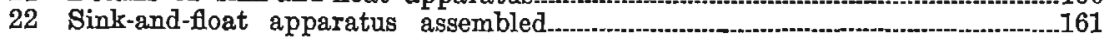




\section{ASH AND SULFUR IN IOWA COALS}

\section{Introduction}

The history of coal production in Towa dates back to 1840 when the first mine was opened in Van Buren county near Farmington. Since that time, with increase in wealth and population of the state, has come great expansion in the mining industry, so that in 1920 according to the United States Geological Survey Iowa ranked eleventh in the list of states with a total net tonnage of $7,813,916$.

Considered from the standpoint of the magnitude and importance of the industry scientific studies of the nature of Iowa coals and the possibilities of improving them for use have been few and inadequate. In general these coals are high in ash, sulfur and volatile matter, qualities that malke them less desirable for domestic use at least than many of those from southern Illinois and Kentucky and from the eastern states, and in competition with them even in the local markets the Iowa fuels suffer some handicap in spite of the advantage of short freight haul. This inferiority, however, may be more apparent than real, since the method of firing is often the controlling factor that dettermines whether or not a coal can give good results. Consider for example two coals, one high in volatile matter, as are most of those of this state, and the other low. These may be equal in thermal value or on the ash- and moisture-free basis the first may be even higher. 'But with improper" combustion condition's, with careless: stoking or with faulty furmace design the high volatile fuel will in all probability give off much smoke and soot, will show low efficiency in generating steam and will in general be much less satisfactory than the one with a high percentage of fixed carbon. 'Or the other hand it is quite conceivable, indeed it has been proved, that under conditions suitable for the high volatile type of fuel in question good efficiencies' and smokeless combustion may be obtained-in other words the high potential heat of the raw coal is converted in a large measure into sensible heat:

The presence of ash and sulfur in large amount, however, is not so easily justified. At best ash is an inert material that must 
be handled both before and after the coal is burned, and when its chemical composition is such that its fusion temperature falls within certain limits troublesome clinkering in the fuel bed or on the grate manifests itself under conditions of forced draft, and this is the case particularly when the pyrite sulfur content is high. But even these difficulties may be mitigated, to some extent at least, by the use of washing processes whereby partial separation of the pure coal substance and the mineral is effected by virtue of the difference in their specific gravities.

Certain phases of the general problem of improving coal quality or of determining the best conditions for using the fuel in its raw state have been under investigation in the Division of Industrial Chemistry at the State University of Iowa since 1921. This paper, which gives the results of preliminary studies of ash and sulfur elimination, is the first of a series designed to cover the whole field so far as opportunity for research may present itself.

To a limited extent investigations of this character have already been made, the most important of which was that carried out jointly by the Iowa State and the National Surveys at the fuel testing plant established in 1904 at St. Louis in connection with the Louisiana Purchase Exposition (1). The number of Iowa coals tested, however, was limited to five, these being selected from mines in Polk, Lucas, Appanoose, Davis and Marion counties and from the standpoint of a complete survey much was left to be desired. Moreover the steam raising qualities of these coals were the chief matters for study, washing tests being quite secondary in importance, made simply in preparation for investigation of coking possibilities. Results showed equivalent evaporation from and at $212^{\circ} \mathrm{F}$. ranging from 7.02 to $7.50 \mathrm{lbs}$. of water per pound of dry coal.

The quality of coke produced from these coals was in the main unsatisfactory from the standpoints both of strength and of sulfur content. It should be noted, however, that the old fashioned bee-hive oven was used and that no special pains were taken to adapt coking conditions to the high volatile coals under consideration. Researches in the constitution of coal and in the principles of coal carbonization made since that time have put 
the art of coke manufacture on a distinctly higher plane and it is quite probable that under modern control a much better product would be obtained-at least so far as density and structure are concerned. Unfortunately the elimination of sulfur is still one of the major problems of fuel technology yet to be solved and little improvement could be expected in this respect.

In a single producer-gas test on a Marion county coal of 17 per cent ash, one electrical horse power hour was obtained with $1.73 \mathrm{lbs}$. of dry fuel whereas under the steam boiler $4.95 \mathrm{lbs}$. were required to produce the same result.

With respect to coal washing it is interesting to note that in July, 1912, the plant of the Iowa Coal Washing Company of Lakonta, Mahaska county (2), capitalized at $\$ 40,000$, began work on screenings from mines in that vicinity. The equipment and methods used as described by Kay conformed to good modern practice and results showed that from low grade material running from 25 to 35 per cent of ash, with the removal of 27 per cent as sink, a product with an ash content as low as 8 to 18 per cent was obtained or in other words the screenings were raised to the standard of the average run-of-mine coal of the state.

\section{Outline of the Present Study}

In the consideration of the possibility of improving the quality of the coals of this or any other state by removal of ash and sulfur it is evident that a laboratory study of the chemical composition and distribution of the offending constituents may be of importance in determining in advance the character of commercial scale work to be employed or that it may even define the extent to which that work can possibly succeed. In recognition of this principle the present study was undertaken in the hope that results might be secured which would lend encouragement to the subsidizing of fuel research in general with more special attention to coal washing.

It has been definitely established that sulfur occurs in bituminous coal in both the inorganic and organic states. Inorganic sulfur appears mainly as pyrite, a mineral of high density distributed throughout the coal in particles ranging in size from microscopic crystals to relatively large lumps of "brass". Be- 
cause of its high specific gravity, which, is about 5, it can easily be separated from coal of a gravity of the order of $1.3 . \ldots$.

To a much smaller extent-usually not more than 0.1 per cent in freshly mined coal-sulfur is found in the oxidized form as the sulfate. This increases slowly with storage in air due to oxidation of pyrite, the reaction being influenced by temperature, moisture content and size of coal particle. It should be noted that in the salt.form its density is relatively low.

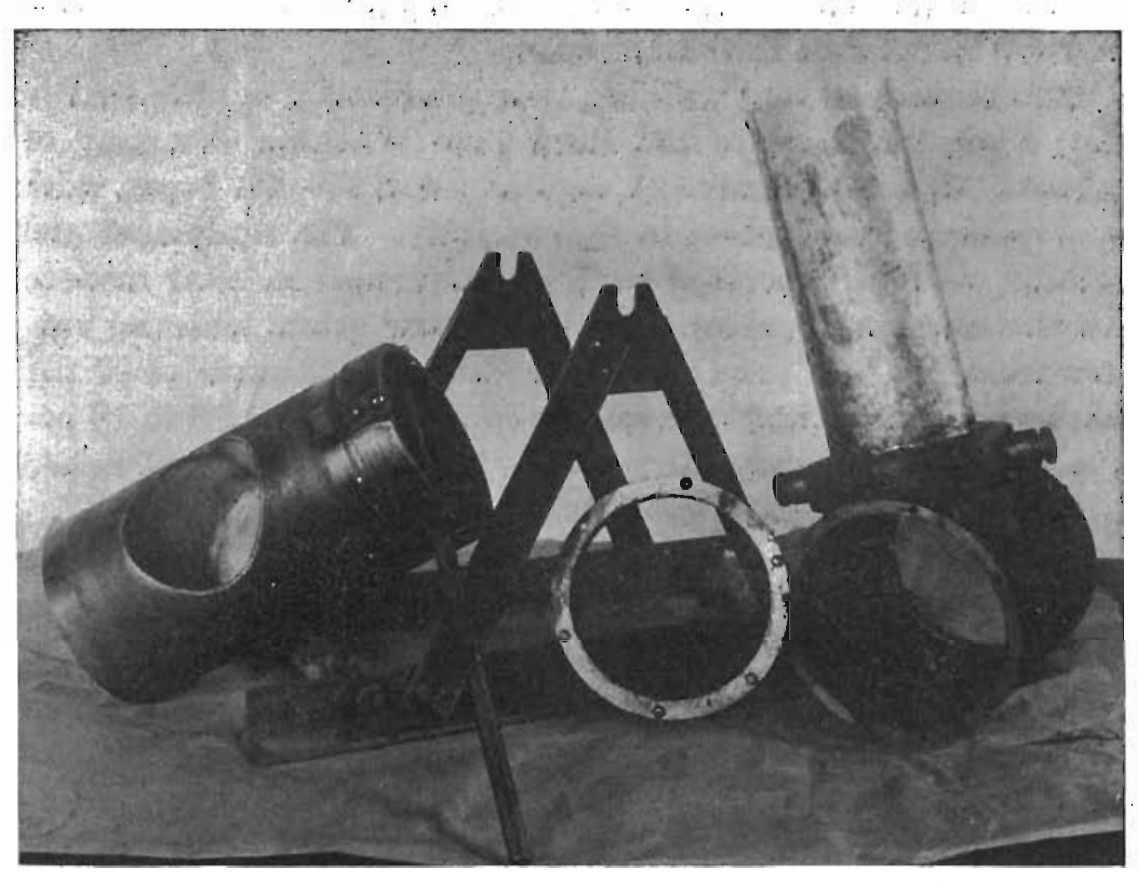

FIG. 21-Details of sink-and-float apparatus.

Organic sulfur, i.e., that combined chemically with carbon in more or less complex arrangement, may also be classified under two heads, for according to Parr and Powell (3) it appears that it unites with two different types of coal substance and is recognized as humic and as resinic or phenolsoluble sulfur. In either case it has a direct bearing on the washing process for it is uniformly distributed throughout the vein in appreciable percentages and because its density is so close to that of the true coal substance it cannot be removed by flotation. 
It is seen, therefore, that the chief value of laboratory studies of sulfur content lies in finding a value below which there ean be no reduction of sulfur content by mechanical processes of separation. For example, if the coal from a given mine arerages two

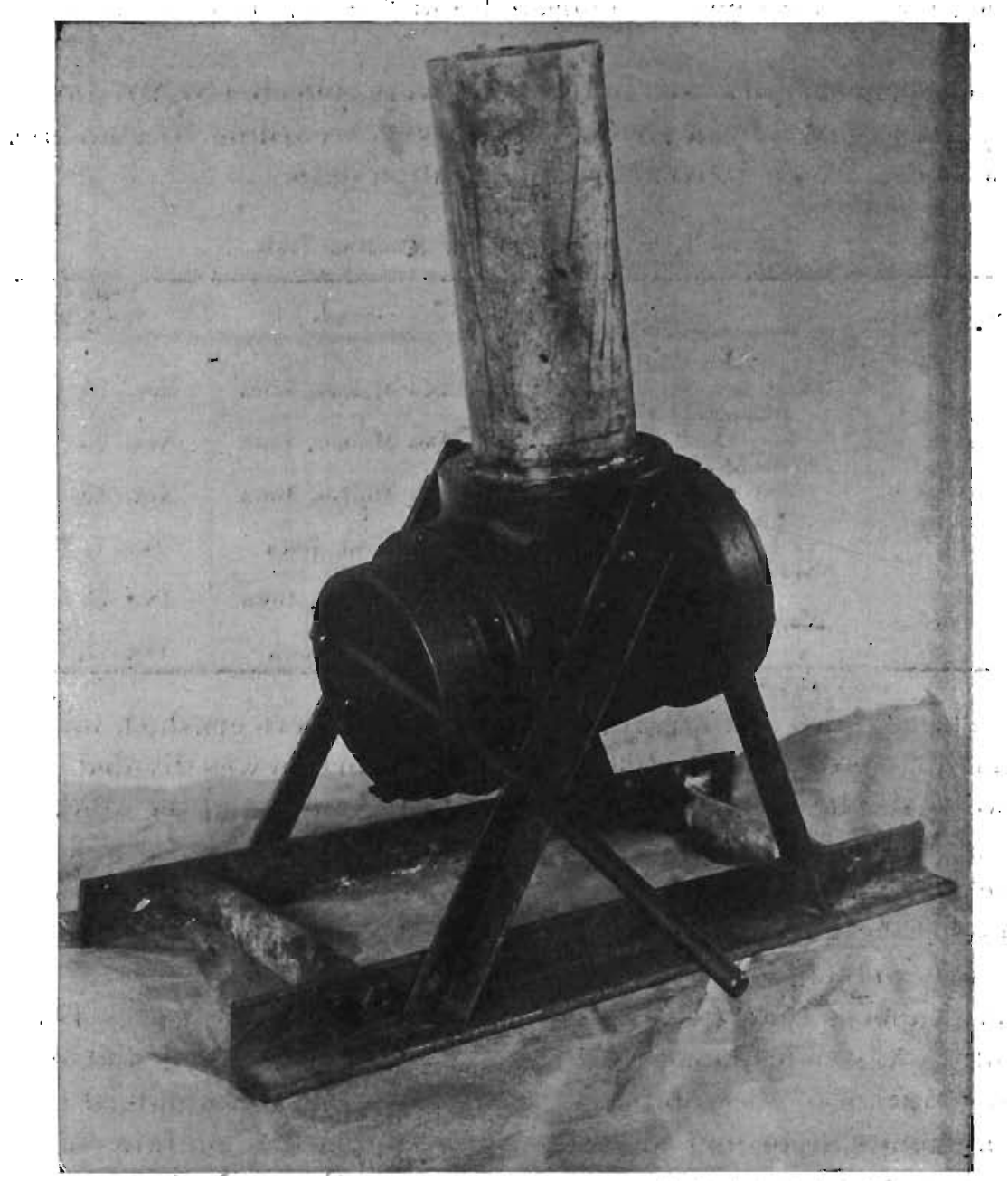

Fra. 22.-Sink-and-float apparatus assembled.

per cent total sulfur and one per cent of this is in the organic form it would of course be impossible to secure a washed:product carrying less than one per cent. Moreover in no case can the pyrite be completely removed so that the minimum that can be 
expected in the clean coal is distinctly greater than the percentage of organic sulfur. It is true of course that small-scale laboratory apparatus gives a more perfect separation than commercial machines and processes but the results are nevertheless indicative of what may be expected and for that reason are valuable.

The coal samples used in this work were collected by Mr. James H. Lees of the Iowa Geological Survey according to standarci methods. Table I gives the identification data.

Table I. Coal Samples for Washing Tests

\begin{tabular}{|c|c|c|c|}
\hline Sample No. & Mine & Place & $\begin{array}{l}\text { Date of } \\
\text { Sampling }\end{array}$ \\
\hline 1 & \multirow{5}{*}{$\begin{array}{c}\text { Beck Coal Co. } \\
\text { NE.1/4 Sec. 24, T. 79, R. } 25 \\
\text { Bloomfield Coal Co. } \\
\text { Sec. 11, T. 79, R. } 24 \\
\text { Des Moines Coal Co., } \\
\text { 33rd St. \& Park Ave. } \\
\text { Sayre Coal Co., } \\
\text { Madrid Shaft } \\
\text { Norwood-White Coal Co., } \\
\text { Mine No. } 6 \\
\text { Norwood-White Coal Co., } \\
\text { Mine No. } 7\end{array}$} & Des Moines, Iowa & Nov. 18, 1921 \\
\hline 3 & & Des Moines, Iowa & Nov. 20,1921 \\
\hline 4 & & $\begin{array}{c}\text { Des Moines, Iowa } \\
\text { Madrid, Iowa }\end{array}$ & $\begin{array}{c}\text { Nov. } 22,1921 \\
\text { Dec. } 7,1921\end{array}$ \\
\hline 5 & & Des Moines, Iowa & Dec. 13, 1921 \\
\hline 6 & & 'Moran, Iowa & \\
\hline
\end{tabular}

The samples on arrival at the laboratory were crushed, mixed and quartered down to 400 grams. This portion was divided into two parts, one of which was ground to 100 mesh and the other to 40. The remainder of the sample. was crushed to pass a No. 4 sieve and it was this material that was used for the sink and float tests that constitute the major part of the work.

The methods of chemical analysis used need no extensive descriptions as they are all fully described in the literature. Total sulfur was determined by the Parr peroxide method and iron by titration of the solution of the fused ash with standard permanganate according to Zimmerman-Reinhardt. Sulfate sulfur determinations were made as outlined by Fraser and Yancy by extraction of the coal substance with dilute hydrochloric acid.

The pyritic iron and sulfur were measured by two methods, one direct, the other indirect. 'In the one case the residue from the hydrochloric acid extraction was further treated with dilute nitric acid while in the other a fresh sample was extracted with 
nitric acid and the sulfur percentages were corrected for sulfate. Organic sulfur was not determined in any.case but was calculated as the difference between total sulfur and the sum of the hydrochloric and nitric acid solubles.

Moisture was determined by drying a one gram sample at $105^{\circ} \mathrm{C}$ for one hour while the ash value was obtained by igniting the dried residue.

In the sink and float tests our procedure followed elosely that used in the University of Mlinois studies. The average true specific gravity of the coals was first measured by the pycnometer method using water to fill the voids. A solution of zine chloride of a specific gravity .05 higher than that of the coal was made up for use as the floating liquid and this was employed in apparatus similar in construction to that designed for similar purposes at the University of Illinois. In using this device, which is shown both knocked down and assembled in figures (21) and (22), the cylinder was filled within two inches of the top with the zinc chloride and the coal sample of 200 grams was immersed and stirred until thoroughly wetted. It was then allowed to stand undisturbed for thirty minutes to permit the heavy particles to sink, after which the valve handle was turned through 180 degrees, thereby separating the float and sink fractions. The bar.rel was next tilted to remove each portion in turn and the solid matter was carefully washed, dried and pulverized for analysis.

In Tables II and III are given the results of these analyses, showing the distribution and form of the iron and sulfur compounds in the unwashed coal. In every case figures given are in percentages based on moisture-free coal.

Table IV shows the distribution of impurities in the two fractions obtained in the washing process.

Table II. Iron Content of Raw Coals Percentages

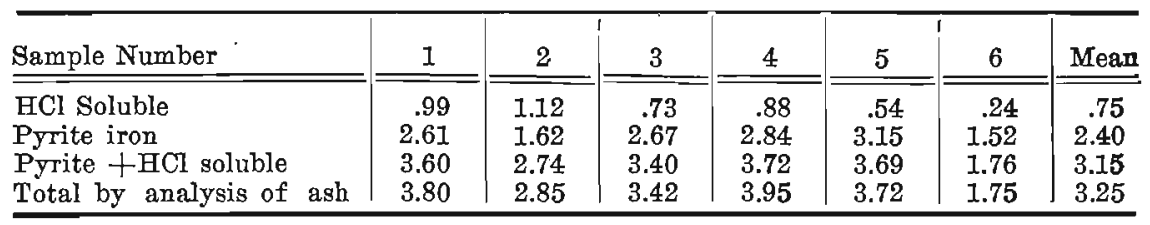



Percentages

\begin{tabular}{|c|c|c|c|c|c|c|c|}
\hline Sample Number & 1 & 2 & ․ ${ }^{i 1} 3^{1}:$ & $\because$ & 5 & 6 & Mean \\
\hline $\begin{array}{l}\text { Pyrite plus } \\
\text {-HCl' soluble } \\
\text { HCl soluble }\end{array}$ & ' 3.10 & $: 2.34$ & $3.38^{\circ}$ & 3.55 & 3.65 & 1.75 & 2.96 \\
\hline (sulfate) & .17 & .29 & .42 & .55 & '. 20 & .15 & .29 \\
\hline $\begin{array}{l}\text { Pyrite sulfur } \\
\text { Pyrite sulfur }\end{array}$ & 2.93 & 2.05 & 2.96 & 3.00 & 3.45 & 1.60 & 2.66 \\
\hline $\begin{array}{l}\text { cálculated from } \\
\text { pyrite iron }\end{array}$ & 2.97 & $\begin{array}{c}1 \\
1.86\end{array}$ & 3.05 & 3.24 & $\begin{array}{l}\cdot 3.60 \\
3.60\end{array}$ & 1.74 & 2.74 \\
\hline $\begin{array}{l}\text { Organic sulfur } \\
\text { by difference }\end{array}$ & $.1 \quad 2.51$ & 68 & 1.99 , & 2.08 & 2.68 & .1 .25 & \\
\hline $\begin{array}{l}\text { Tatal sulfur by } \\
\text { bomb }\end{array}$ & 5.61 & 3.02 & 5.37 & 5.63 & 6.33 & $3 \vdots 00$ & $\begin{array}{l}1.86 \\
4.82\end{array}$ \\
\hline
\end{tabular}

Table IV. Distribution of Iron and Sulfur in Float and Sink Fractions Percentages

\begin{tabular}{|c|c|c|c|c|c|c|c|}
\hline Sample Number & $\cdot 1$ & 2 & $.3: 1$ & 4 & 5 & 6 & Mean \\
\hline $\begin{array}{l}\text { Moisture in } \\
\text { original }\end{array}$ & 9.84 & 6.42 & 5.56 & 5.96 & 2.48 & 7.56 & 6.30 \\
\hline $\begin{array}{l}\text { Percentage of } \\
\text { flaat }\end{array}$ & 72.10 & 81.80 & 66.10 . & 73.00 & $=83.50$ & 84.10 & 76.60 \\
\hline $\begin{array}{l}\text { Percentage of } \\
\text { sink } \\
\text { Ash }\end{array}$ & 27.90 & 18.20 & 33.90 & 27.00 & : 17.50 & 15:90: & 23.40 \\
\hline Original & 13.61 & 11.91 & 12.84 & 12.22 & 12.72 & 9.97 & 12.21 \\
\hline Float & 9.40 & 8.88 & 19.74 & 7.90 & 7.33 & .6 .83 & 8.35 \\
\hline $\begin{array}{l}\text { Sink } \\
\text { Percentage }\end{array}$ & 26.42 & 35.23 & 32.45 & 38.82 & 46.15 & 38.90 & 36.33 \\
\hline $\begin{array}{l}\text { Removed } \\
\text { Sulfur }\end{array}$ & 54.20 & 53.80 & 85.80 & 85.7 .0 & 63.50 & 62.00 & 67.50 \\
\hline Original & 5.61 & $3: 02$ & $5.37^{\circ}$ & 5.63 & 6.33 & 3.00 & 4.83 \\
\hline Float & 3.50 & 1.78 & 3.60 & 3.53 & 4.07 & 1.75 & .3 .04 \\
\hline Sink & 7.75 & 6.68 & 9.13 & 11.50 & 14.50 & 9.02 & 9.76 \\
\hline Percentage & & & . & & & - & \\
\hline Iron & 38.58 & 40,30 & 57.60 & $i 55.15$ & 40.10 & 47.75 & 46.58 \\
\hline Original & 3.80 & 2.85 & 3.42, & 3.95 & 3.72 & 1.75 & .3 .25 \\
\hline Float & 2.50 & 1.65 & 2.25 & 2.21 & 1.68 & 1.02 & 1.89 \\
\hline $\begin{array}{l}\text { Sink } \\
\text { Percentage }\end{array}$ & 7.49 & 6.10 & 6.05 & 8.95 & $14: 80$ & 6.12 & 8.25 \\
\hline Removed & 55.00 & 39.00 & 59.98 & 61.20 & 69.60 & 55.60 & 56.73 \\
\hline
\end{tabular}

Little comment on the figures submitted is necessary ofher than to stress the fact that the mean sulfur value of the float portions as shown in Table IV is well above that for mean organic sulfur given in Table III which may be taken as the possible minimum. In other words sulfur elimination even under the most favorable conditions is not an efficient process. Figures 
taken from Table IV show that in order to lower the sulfur content of the average coal from 4.83 to 3.04 per cent and the average ash from 12.21 to 8.35 per cent, reductions of 46.5 and 67.5 per cent respectively, it is necessary to discard 23.4 per cent of the original tonnage. Of this 23.4 per cent, however, 10.3 per cent is ash and sulfur so that only 13.1 per cent of the original tonnage is discarded or converted into what may be classified as low grade material. Rather wide variation is observed in individual coals and this points to the necessity of studying each coal separately before definite conclusions concerning the advisability of attempting large-scale washing can be reached.

We may say in conclusion that this study has covered but a small part of the field but it is nevertheless indicative of what might profitably be done for all the coals of the state as opportunity presents itself and this could then be followed by carload washing tests employing semi-plant size machinery.

\section{REFERENCES}

(1) Iowa Geological Survey 19, 401; 1908.

(2) Proc. Iowa Acad. Sci. XXII, 225.

(3) Univ. of Ill. Fng. Expt. Sta. Bull. 125, 12; 1921.

(4) Idem. 23; 1921.

(5) Idem. 25: 1921. 


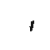

